\title{
Serum prostate-specific antigen as a predictor of prostate volume in Sudanese patients with benign prostatic hyperplasia
}

\author{
Awad Ali M. Alawad ${ }^{1 *}$, Faisal H. Younis ${ }^{1}$, Abdalla Mahgoub Eltoum ${ }^{2}$, Sana Azmi Abdelgani ${ }^{2}$ \\ ${ }^{1}$ Assistant professor, Department of Surgery, Faculty of Medicine, University of Medical Sciences and Technology, Sudan \\ ${ }^{2}$ Department of Surgery, University Charity Teaching Hospital, Sudan \\ *Corresponding author E-mail: awadali82@hotmail.com
}

\begin{abstract}
Background: Benign prostatic hyperplasia (BPH) is now recognized as one of the principal medical problems facing the male population in Sudan.

Objective: The aim of this study is to assess the ability of serum prostate-specific antigen (PSA) to predict prostate volume (PV) in patients with benign prostatic hyperplasia (BPH).

Materials and Methods: This is retrospective observational case-detection hospital based study. Eighty medical records of patients with an enlarged prostate attending the urology clinic at University Teaching Hospital were enrolled. This research was conducted in University Charity Teaching Hospital, Khartoum, Sudan.

Results: Enrolled patients had a median age of 63.5 years (51 to 94), a mean PSA of $2.94 \mathrm{ng} / \mathrm{mL}$ and a mean PV of $46.96 \mathrm{~mL}$, respectively. There is linear relationship between PSA levels and prostate size. Those with a prostate size of $>40 \mathrm{ml}$ were found to be more likely to have high PSA mean level. PSA mean values were found to be associated with age ( $\mathrm{P}<0.006)$.

Conclusion: Serum prostate specific antigen (PSA) is significantly correlated with prostate volume in Sudanese men. PSA may be a useful tool in making therapeutic decisions and follow-up management in BPH patients.
\end{abstract}

Keywords: Serum Prostate Specific Antigen; Prostate Volume; Benign Prostatic Hyperplasia.

\section{Introduction}

Benign prostatic hyperplasia (BPH), diagnosed by the presence of benign prostate enlargement and lower urinary tract symptoms (LUTS), has been considered to be a chronic and progressive disease. Because baseline prostate volume (PV) has been linked to the progression of $\mathrm{BPH}$ (e.g., acute urinary retention and surgery for $\mathrm{BPH})$, PV has been included as a useful tool in treatment guidelines (Kwon et al. 2013). Therefore, it is clear that knowledge of individual PV would be beneficial for everyday management of patients presenting to physicians. This undertaking has some problems, most notably fact that digital rectal examination is relatively inaccurate in measuring the correct prostate size when measured by either transrectal ultrasound (TRUS) or other imaging modalities, such as computerized tomography or magnetic resonance imaging (Tubaro et al. 2003). Because imaging modalities accompany financial burden and limited reproducibility, it is reasonable to search for alternative parameters that could be used instead of PV.

Prostate-specific antigen (PSA) is a marker for prostate cancer and $\mathrm{BPH}$. The relationship between PSA and PV has been examined frequently in men with BPH, in part to determine how PSA can be used to predict PV (Bohnen et al. 2007, Choi et al. 2013, Chung et al. 2006, Kalish et al. 1994, Mochtar et al. 2003, Roehrborn et al. 2000, Shim et al. 2007). These studies have consistently shown a positive correlation between PSA and PV. However, most studies of the relationship between PSA and prostate volume have originated from developed countries, and few studies have been conducted in Africa.
Thus, we performed a study to determine the predictive power of PSA for prostate volume in Sudanese patients with biopsy proven benign prostatic hyperplasia.

\section{Materials and methods}

This is retrospective observational case-detection hospital based study. Eighty medical records of patients with an enlarged prostate attending the urology clinic at University Teaching Hospital were enrolled. This research was conducted in University Charity Teaching Hospital, Khartoum, Sudan.

Demographic details, clinical presentation, Serum prostatespecific antigen (PSA) profiles and assessment of prostate volume (PV) of all patients were entered into our study proforma. For PSA testing, patients' serum was obtained before prostatic manipulations. PV was measured with transabdominal ultrasound and PV was defined by measuring the height $(\mathrm{H})$, width $(\mathrm{W})$, and length (L) of the prostate from two selected orthogonal views and calculating the volume $(\mathrm{V})$ as that of the corresponding ellipsoid formula: $\mathrm{V}=0.52 \times \mathrm{W} \times \mathrm{H} \times \mathrm{L}$ (Choi et al. 2013).

Exclusion criteria were patients with a history of receiving 5alpha reductase inhibitor therapy and those with a history of invasive surgical treatment of benign prostatic hyperplasia (BPH), such as transurethral resection or laser prostatectomy. Patients with a history of acute prostatitis, with a history of urinary retention within the past month, or lacking data on any of the aforementioned parameters were excluded. Prostate cancer patients with results confirmed by subsequent TRUS-guided prostate biop- 
sy were excluded. Only patients proven to have benign results by the prostate biopsy were included in this study. Patients with PSA above $20 \mathrm{ng} / \mathrm{mL}$ were also omitted to decrease the possibility of occult prostate cancer. After all exclusions, 80 men were enrolled in this study.

All summary statistics are stated with $95 \%$ confidence limits. A method appropriate for small samples was applied to the percentages and odds ratios were derived using logistic regression methods (SPSS version 17). P-value of less than 0.05 was considered statistically significant.

\section{Results}

The mean age of patients was 63.5 years and the age ranged from 51 to 94 years. When the patients $(n=80)$ were classified according to their age, it was noticed that $31(38.8 \%)$ of them were found to have fallen within the age group of (51-61) years, Whereas 27 $(33.8 \%)$ fell in the age group (62-72), with an average age of 65.93 years and a standard deviation, as a measure of dispersion (variability) of 8.7 years. Sixty three $(78.7 \%)$ patients were married and $17(21.2 \%)$ were unmarried. Geographically, $20(25 \%)$ patients were from the rural area and $60(75 \%)$ from urban area. General and demoghraphic characteristics are shown in Table 1.

Table 1: General and Demographic Characteristics of the Patients $(\mathrm{No}=80)$

\begin{tabular}{ll}
\hline Item & Patients No $(\%)$ \\
\hline Age (year) & $31(38.8 \%)$ \\
$51-61$ & $27(33.8 \%)$ \\
$62-72$ & $20(25 \%)$ \\
$73-83$ & $2(2.4 \%)$ \\
$84-94$ & $63(78.8 \%)$ \\
\hline Marital Status & $17(21.2 \%)$ \\
Married & \\
Not married & $60(75 \%)$ \\
\hline Residence & $20(25 \%)$ \\
Urban & \\
Rural & $33(41.2 \%)$ \\
\hline Prostate volume (ml) & $30(37.5 \%)$ \\
20- 40 & $12(15 \%)$ \\
$41-61$ & $5(6.2 \%)$ \\
62- 82 & \\
$83-103$ &
\end{tabular}

When the patients were classified according to the size of the prostate it was found that $33(41.2 \%)$ of them were found to have a prostate size $(20-40 \mathrm{~g})$. Whereas, $30(37.5 \%)$ were found to have a prostate size of (41-61 g). Mean PSA value was of $2.94 \mathrm{ng} / \mathrm{mL}$ and a mean PV of $46.96 \mathrm{~mL}$. PSA value (mean value) as an independent variable was found to be associated with the prostate size (Tab. 2). Those with a prostate size of $>40 \mathrm{~g}$ were found to be more likely to have high PSA mean level $(\mathrm{P}<0.009)$.

Table 2: Comparison of the PSA Means According To the Volume of Prostate $(\mathrm{N}=80)$

\begin{tabular}{lllll}
\cline { 1 - 4 } \multicolumn{2}{l}{ Volume of prostate } & \multicolumn{4}{c}{ Prostate Specific Antigen } & \\
$(\mathrm{ml})$ & $\mathrm{N}$ & Mean & Std. Deviation & Std. Error \\
\cline { 1 - 4 }$(20-40)$ & 33 & 1.9 & 2 & 0.355 \\
$(41-61)$ & 30 & 3.5 & 2.8 & 0.507 \\
$(62-82)$ & 12 & 4 & 2.1 & 0.619 \\
$(83-103)$ & 5 & 3.9 & 0.9 & 0.424 \\
Total & 80 & 2.9 & 2.5 & 0.275 \\
One way ANOVA (p. value $=0.009)^{* *}$ & & \\
\hline
\end{tabular}

Figure 1 represents, graphically, the relationship between PSA levels and prostate size. Looking into the chart one could notice there is linear relationship between the two variables $(\mathrm{P}=0.001)$. PSA mean values were found to be associated with age $(\mathrm{P}<0.006)$ (Fig 2). A positive weak correlation was also found between PSA mean levels and age of the patient.

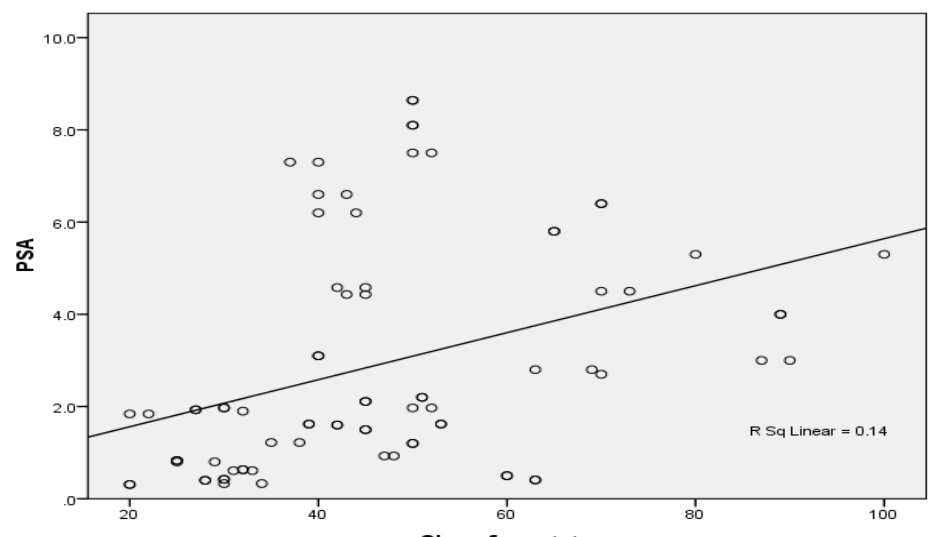

Fig. 1: Relationship between PSA and Prostate Size (Correlation (R) $=0.375$ )

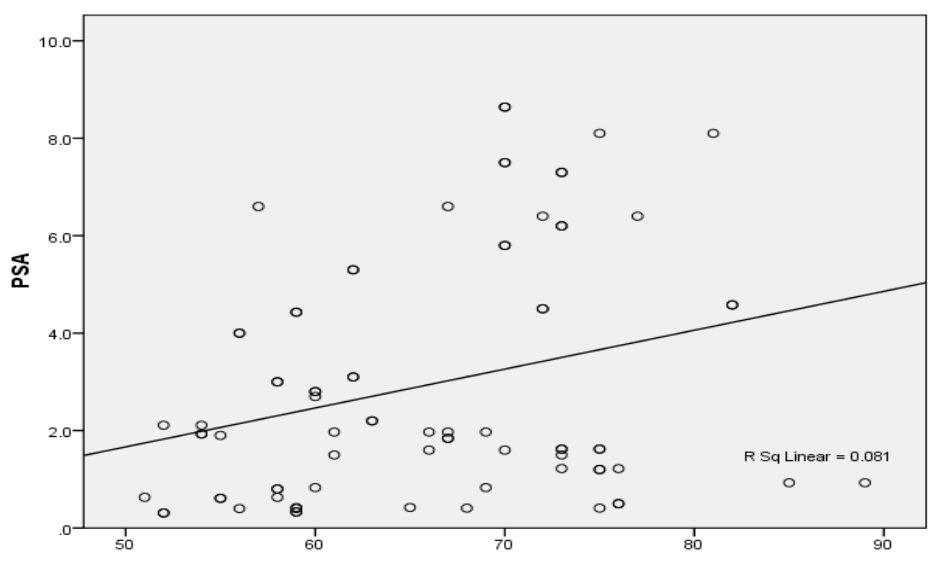

Fig. 2: Relationship between PSA and Age (Correlation $(\mathrm{R})=0.284$ ) 


\section{Discussion}

Prostate volume (PV) is perhaps the most extensively studied risk factor for BPH progression. Men with a PV of $\geq 30 \mathrm{~mL}$ are more likely to have moderate-to-severe symptoms (3.5-fold increase), decreased flow rates (2.5-fold increase), and urine retention (threeto four-fold increase) than are men with a PV $<30 \mathrm{~mL}$ (Park et al 2013). So, PV information has become more and more important because the PV strongly predicts BPH-related morbidity such as acute urinary retention and the need for surgery.

Generally, the typical method of measuring PV is transrectal ultrasound (TRUS) (Stravodimos et al. 2009). But, TRUS is relatively painful. Moreover, TRUS is also not cost-effective and routine evaluation of patients with BPH. In our setting, TRUS is not available. Additionally, DRE is simple to perform and practical for estimating the PV, but it has been revealed that DRE underestimates the real prostate size.

Rosenberg first assessed the PSA threshold as a predictor of PV by characterizing the relationship between PV and serum PSA in men with symptomatic BPH in the Proscar Long-Term Efficacy and Safety study (Kravchick et al. 2007). Because PV is strongly related to serum PSA in men with no evidence of prostate cancer, they suggested that serum PSA can be used to estimate the degree of prostate enlargement accurately enough for it was a useful tool in therapeutic decision making. Previous studies have focused on the relationship between serum PSA and PV (Choi et al. 2013 , Furuya et al. 2001, Jara Rascon et al. 2005, Kwon et al. 2013, Mochtar et al. 2003, Park et al. 2013, Roehrborn et al. 2000, Shim et al. 2007). According to these studies on serum PSA, there were strong relationship with PV, and they found that PSA would be able to predict the PV. Other studies on free PSA showed a loglinear relationship with PV and free PSA predicted PV more precisely than total PSA in BPH patients (Canto et al. 2004, Lazzeri et al. 2013). The ability of PSA to predict PV increased with prostate size. In our study total PSA mean values were found to be associated with the size of the prostate; the greater the size of the prostate, the higher the PSA value. PSA mean value were also found to be associated with age; the older the patient, the greater the PSA mean value. In our log-linear correlation analysis, the serum PSA cutoff value was 1.47 to detect a PV. $30 \mathrm{ml}$ and 2.8 to detect a PV. $.35 \mathrm{ml}$. However, its level of relationship and accuracy of predicting PV was relatively low when compared to previous studies in Western countries.

To the best of our knowledge, this study is the first to examine the relationship between PSA and PV in Sudanese men, and to show the efficacy of PSA at predicting more precise PV in Sudanese men. Because of the ability to obtain more accurate estimates of the PV without the help of more expensive, invasive diagnostic evaluations, PSA would introduce a more reasonable contribution in the proper management of patients with $\mathrm{BPH}$.

\section{Conclusion}

Serum prostate specific antigen (PSA) is significantly correlated with prostate volume in Sudanese men. PSA may be a useful tool in making therapeutic decisions and follow-up management in BPH patients. Further studies are required to elucidate the exact interactions between PSA and PV in prospective controlled studies.

\section{References}

[1] Bohnen AM, Groeneveld FP \& Bosch JL (2007): Serum prostatespecific antigen as a predictor of prostate volume in the community: the Krimpen study. Eur Urol 51, 1645-1652; discussion 1652-1643.

[2] Canto EI, Singh H, Shariat SF, Lamb DJ, Mikolajczyk SD, Linton HJ, Rittenhouse HG, Kadmon D, Miles BJ \& Slawin KM (2004): Serum BPSA outperforms both total PSA and free PSA as a predictor of prostatic enlargement in men without prostate cancer. Urology 63, 905-910; discussion 910-901.

[3] Choi H, Park JY, Shim JS, Kim JH \& Bae JH (2013): Free prostatespecific antigen provides more precise data on benign prostate volume than total prostate-specific antigen in korean population. Int Neurourol J 17, 73-77.

[4] Chung BH, Hong SJ, Cho JS \& Seong DH (2006): Relationship between serum prostate-specific antigen and prostate volume in Korean men with benign prostatic hyperplasia: a multicentre study. BJU Int 97, 742-746.

[5] Furuya Y, Ohta S, Sato N, Kotake T \& Masai M (2001): Prostatespecific antigen, prostate volume and transition zone volume in Japanese patients with histologically proven benign prostatic hyperplasia. Int Urol Nephrol 33, 645-648.

[6] Jara Rascon J, Subira Rios D, Lledo Garcia E, Martinez Salamanca JI, Moncada Iribarren I, Cabello Benavente R \& Hernandez Fernandez C (2005): [Parameters with possible influence in PSA adjusted for transition zone volume]. Actas Urol Esp 29, 473-480.

[7] Kalish J, Cooner WH \& Graham SD, Jr. (1994): Serum PSA adjusted for volume of transition zone (PSAT) is more accurate than PSA adjusted for total gland volume (PSAD) in detecting adenocarcinoma of the prostate. Urology 43, 601-606.

[8] Kravchick S, Bunkin I, Peled R, Yulish E, Ben-Dor D, Kravchenko Y \& Cytron S (2007): Patients with elevated serum PSA and indwelling catheter after acute urinary retention: prospective study of 63 patients with 7-year follow-up. J Endourol 21, 1203-1206.

[9] Kwon H, Kang HC \& Lee JH (2013): Relationship between predictors of the risk of clinical progression of benign prostatic hyperplasia and metabolic syndrome in men with moderate to severe lower urinary tract symptoms. Urology 81, 1325-1329.

[10]Lazzeri M, Haese A, Abrate A, de la Taille A, Redorta JP, McNicholas T, Lughezzani G, Lista G, Larcher A, Bini V, Cestari A, Buffi N, Graefen M, Bosset O, Le Corvoisier P, Breda A, de la Torre P, Fowler L, Roux J \& Guazzoni G (2013): Clinical performance of serum prostate-specific antigen isoform [-2]proPSA (p2PSA) and its derivatives, \%p2PSA and the prostate health index (PHI), in men with a family history of prostate cancer: results from a multicentre European study, the PROMEtheuS project. BJU Int 112, 313-321.

[11] Mochtar CA, Kiemeney LA, van Riemsdijk MM, Barnett GS, Laguna MP, Debruyne FM \& de la Rosette JJ (2003): Prostate-specific antigen as an estimator of prostate volume in the management of patients with symptomatic benign prostatic hyperplasia. Eur Urol 44, 695-700.

[12]Park DS, Oh JJ, Hong JY, Hong YK, Choi DK, Gong IH, Hwang JH \& Kwon SW (2013): Serum prostate-specific antigen as a predictor of prostate volume and lower urinary tract symptoms in a communitybased cohort: a large-scale Korean screening study. Asian J Androl 15 , 249-253.

[13]Roehrborn CG, McConnell J, Bonilla J, Rosenblatt S, Hudson PB, Malek GH, Schellhammer PF, Bruskewitz R, Matsumoto AM, Harrison LH, Fuselier HA, Walsh P, Roy J, Andriole G, Resnick M \& Waldstreicher J (2000): Serum prostate specific antigen is a strong predictor of future prostate growth in men with benign prostatic hyperplasia. PROSCAR long-term efficacy and safety study. J Urol $163,13-20$.

[14]Shim HB, Lee JK, Jung TY \& Ku JH (2007): Serum prostate-specific antigen as a predictor of prostate volume in Korean men with lower urinary tract symptoms. Prostate Cancer Prostatic Dis 10, 143-148.

[15] Stravodimos KG, Petrolekas A, Kapetanakis T, Vourekas S, Koritsiadis G, Adamakis I, Mitropoulos D \& Constantinides C (2009): TRUS versus transabdominal ultrasound as a predictor of enucleated adenoma weight in patients with BPH: a tool for standard preoperative work-up? Int Urol Nephrol 41, 767-771.

[16] Tubaro A, Trucchi A \& Miano L (2003): Investigation of benign prostatic hyperplasia. Curr Opin Urol 13, 17-22. 